Case Report

\title{
Uterine angioleiomyoma complicated by consumptive coagulopathy
}

\author{
Marci Handler ${ }^{1}$, Fariborz Rezai ${ }^{*}$, Kristin G. Fless ${ }^{1}$, Mikhail Litinski ${ }^{1}$, Paul C. Yodice ${ }^{1}$ \\ Saint Barnabas Medical Center, Livingston, NJ, USA
}

\section{A R T I C L E I N F O}

\section{Article history:}

Received 17 February 2012

Accepted 31 March 2012

Available online 6 April 2012

\section{Keywords:}

Angioleiomyoma

Angiomyoma

Vascular leiomyoma

Uterus

Consumptive coagulopathy

\section{Introduction}

Angioleiomyoma or vascular leiomyoma is an unusual type of benign tumor originating from mesenchymal tissue. This type of leiomyoma is composed of smooth muscle cells and thick-walled vessels. It is frequently seen on the skin of the lower extremities in adults aged forty to sixty (Culhaci et al., 2006; Weiss and Goldblum, 2001). It is exceedingly rare for this tumor to be found in a location other than the lower extremities. From 1966 to 2007, only 11 cases of uterine angioleiomyoma were reported in the current English literature (Cobellis et al., 2007; Culhaci et al., 2006; Hakverdi et al., 2009; Hsieh et al., 2003). In angioleiomyomas, as with the majority of benign tumors, features such as consumptive coagulopathy are not typically seen. We present the rare case of consumptive coagulopathy secondary to a large degenerated uterine angioleiomyoma.

\section{Case report}

A 38-year-old nulligravida African-American woman presented to her local medical practitioner four months prior complaining of an enlarging abdomen and early satiety. She had previously experienced $85 \mathrm{~kg}$ of desired, voluntary weight loss over the preceding eighteen months and noted that her abdominal weight loss was disproportionate to the rest of her body. Her only significant past medical history

\footnotetext{
* Corresponding author. Fax: +1973 3228410.

E-mail addresses: marcihandler@gmail.com (M. Handler), frezai@barnbashealth.org (F. Rezai), kfless@barnabashealth.org (K.G. Fless), mlitinski@barnabashealth.org (M. Litinski), pyodice@barnabashealth.org (P.C. Yodice). ${ }^{1}$ Fax: + 19733228410
}

revealed adenomyosis which was diagnosed after exploratory laparotomy six years prior. She reported a menstrual history which was notable for menorrhagia over the previous ten years. She denied a previous history of blood transfusion, deep vein thrombosis or easy bruising. The patient's family history was negative for blood coagulopathies. Her home medications included iron and vitamin B12 supplements. An outpatient computed tomography (CT) scan at that time demonstrated a large $25 \times 28 \times 25 \mathrm{~cm}$ abdominal mass with central areas of necrosis. Both physical examination and CT scan were unable to differentiate the mass as either uterine or adnexal in origin. The patient did not seek further treatment at that time.

On admission, four months after her initial physician visit, the patient presented to the hospital with complaints of excessive menstrual vaginal bleeding with dime-sized clots and abdominal cramping pain for the previous five days. Physical examination revealed a large non-tender abdominopelvic mass estimated to be equivalent in size to a 40 weeks' gestation. Coagulation studies upon admission were consistent with consumptive coagulopathy. This was evidenced by the following: platelet count $69 \times 10^{3} / \mathrm{mm}^{3}$ (normal range: $150-140 \times 10^{3} / \mathrm{mm}^{3}$ ), activated partial thromboplastin time $>250 \mathrm{~s}$ (normal range: $20-25 \mathrm{~s}$ ), prothrombin time $>100 \mathrm{~s}$ (normal range: $11-15 \mathrm{~s}$ ), INR $>7.9$ (normal range: $1.0-1.2$ ), fibrinogen $<40 \mathrm{mg} / \mathrm{dL}$ (normal range: $200-400 \mathrm{mg} / \mathrm{dL}$ ), D-dimer $>5250$ units (normal range: $<0.4 \mu \mathrm{g} / \mathrm{mL}$ ). Hemoglobin $(\mathrm{Hb})$ was $6.3 \mathrm{~g} / \mathrm{dL}$ and MCV $93.8 \mathrm{fL}$ (normal range: 80-100 fL). Red cell morphology demonstrated anisocytosis, poikilocytosis, and schistocytes. CT scan (Fig. 1) of the abdomen and pelvis with contrast demonstrated a necrotic mass arising out of the pelvis measuring $29.2 \times 28.6 \times 30 \mathrm{~cm}$ (previously $25 \times 28 \times 25 \mathrm{~cm}$ ), an enlargement from the previous scan four months prior.

Two days after admission, the patient was taken for laparotomy. $\mathrm{Hb}$ was $5.7 \mathrm{~g} / \mathrm{dL}$ prior to the procedure. The tumor was completely removed with total abdominal hysterectomy and bilateral salpingooophorectomy (Fig. 2). The patient refused fresh frozen plasma, citing religious reasons, as the patient is a Jehovah's Witness. She accepted 10 units of cryoprecipitate (fibrinogen, von Willebrand factor, factor VIII, factor XIII, fibronectin). Of the $800 \mathrm{~mL}$ estimated blood loss intraoperatively, cell saver returned $350 \mathrm{~mL}$ to the patient.

On gross examination, the uterus and cervix weighed $9300 \mathrm{~g}$ and measured $28 \times 27.5 \times 17 \mathrm{~cm}$. The myometrium showed several, graywhite, rubbery masses with whorled surfaces. The largest myometrial mass measured $26 \mathrm{~cm}$ in greatest diameter with a trabeculated, cystic and hemorrhagic, sponge-like appearance (Fig. 3). Additionally, separate myometrial masses were present, the largest measuring $4 \mathrm{~cm}$. The cervix and both tubes were unremarkable.

Microscopic examination of the largest myometrial mass revealed interlacing smooth muscle bundles without pleomorphism, intermingled 


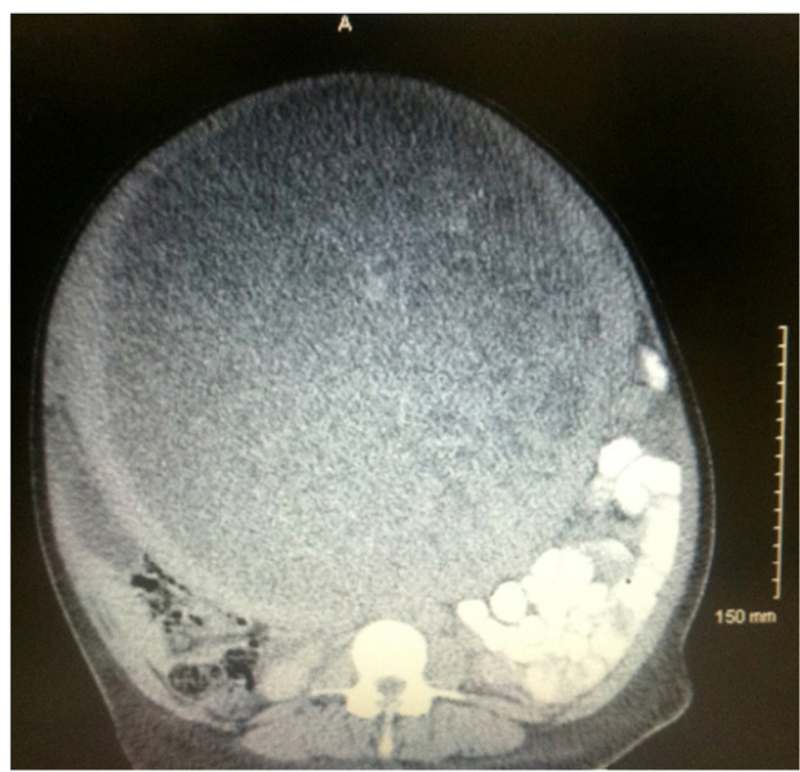

Fig. 1. Abdominal and pelvic CT with contrast reveals a large necrotic mass.

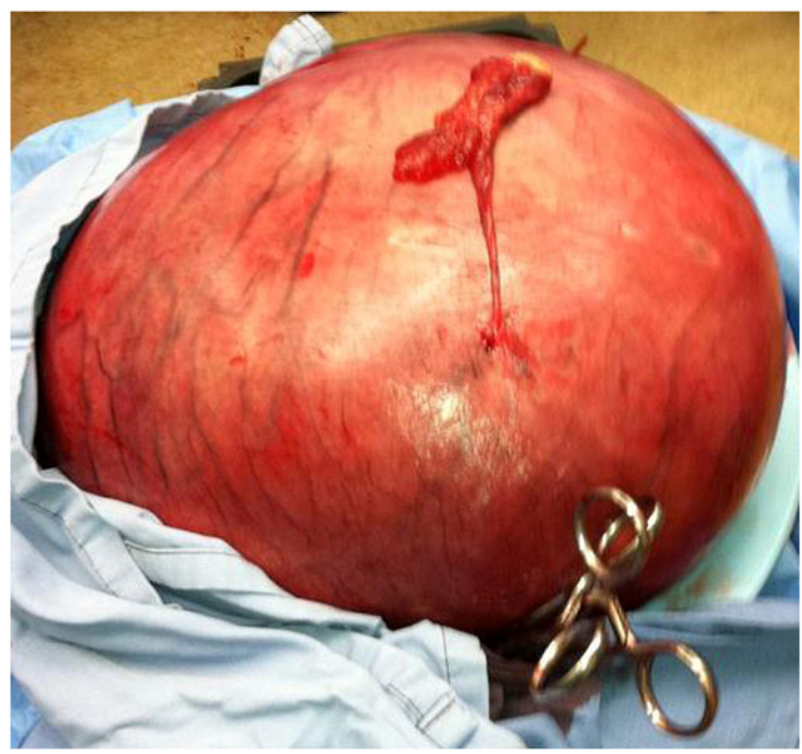

Fig. 2. Gross view of the uterus containing the tumor.

with abundant thick-walled vessels. Large areas of cystic degeneration were noted. Organizing thrombi were noted in some of the dilated vascular channels. Based on these findings, a pathologic diagnosis of angioleiomyoma was made.

One day after surgery, the patient's coagulation profile revealed $\mathrm{Hb} 6.8 \mathrm{~g} / \mathrm{dL}$ with a slightly higher platelet count of $72 \times 10^{3} / \mathrm{mm}^{3}$, activated partial thromboplastin time $30.8 \mathrm{~s}$, prothrombin time $15 \mathrm{~s}$, and INR 1.3. Postoperative recovery was uneventful and the patient was released from the hospital six days later. At the time of discharge, coagulopathy resolved with a platelet count $186 \times 10^{3} / \mathrm{mm}^{3}$, activated partial thromboplastin time $34.4 \mathrm{~s}$, and INR 1.5.

\section{Discussion}

It is well documented that malignant tumors frequently cause hemostatic abnormalities. It is evidenced that $10-15 \%$ of metastatic tumors are

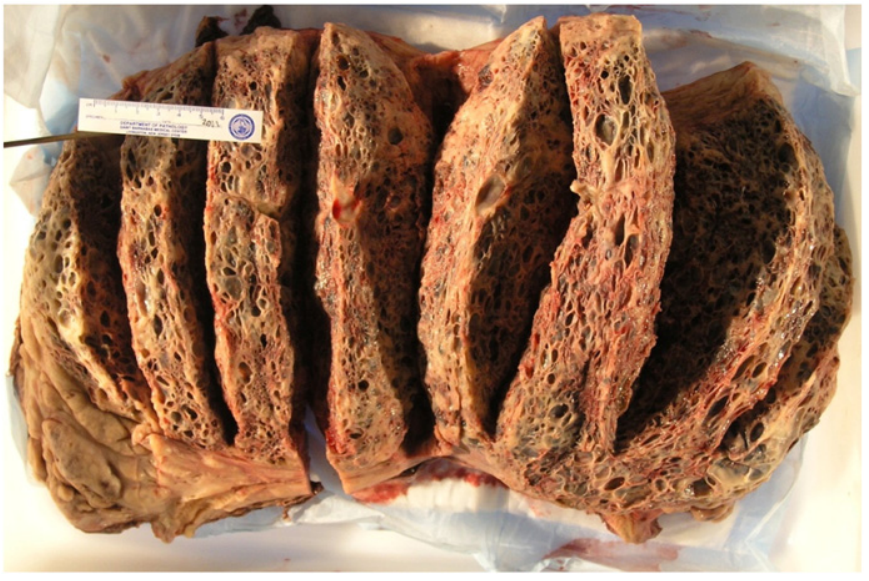

Fig. 3. Gross examination of the neoplasm showing a cystic appearance.

known to cause consumptive coagulopathy (Duran and Tannock, 2006; Levi and Ten Cate, 1999; Ten Cate et al., 1999). It is extremely uncommon, however, for benign tumors to cause such disturbances. Angioleiomyoma or vascular leiomyoma is an unusual benign smooth muscle tissue tumor, commonly found in the head, neck and lower extremities (Cobellis et al., 2007; Culhaci et al., 2006; Hakverdi et al., 2009; Hsieh et al., 2003). Very few cases of these tumors have been described at sites other than these locations. Angioleiomyomas are composed of smooth muscle cells and thick-walled vessels. Our case presents the atypical occurrence of a large angioleiomyoma of the uterus activating consumptive coagulopathy.

A MEDLINE search revealed only three cases of uterine leiomyoma found to be the cause of consumptive coagulopathy, none of which of the vascular variant (Harris et al., 1982). Very large tumors, such as the one seen in this patient, can demonstrate extensive ischemic and degenerative changes. Harris et al. and Caputo et al. theorized that blood stagnation present in the tumor's vessels leads to the formation of thrombi. This collection of thrombi occludes these large vessels and results in ischemic injury. Procoagulant factors are released which result in the consumption of red blood cells, coagulation factors, platelets and thrombin. Fibrin degradation products are formed from the cleaving of fibrinogen by plasmin. The continual consumption of clotting factors and the localization of cleaved microthrombi are thus responsible for the thrombosis and hemorrhage seen in consumptive coagulopathy (Caputo and Kabour-shakir, 1993; Harris et al., 1982).

The mainstay of treatment for angioleiomyoma is surgical removal. Amelioration of coagulopathy involves treating the underlying cause, in this case, removal of the large tumor. Surgical removal of the angioleiomyoma subsequently corrected the patient's consumptive coagulopathy as well as alleviated the patient's discomfort and vaginal bleeding.

Conflict of interest statement

The authors of this manuscript declare that there are no conflicts of interest.

\section{References}

Caputo, R., Kabour-shakir, A., 1993. Chronic disseminated intravascular coagulation caused by a uterine leiomyoma. J. Reprod. Med. 38 (9), 737-740 (Sep)..

Cobellis, L., Pecori, E., Rigatti, F., Scaffa, C., Rotondi, M., Messalli, E.M., 2007. A rare case of female pelvic mass: angioleiomyoma of the broad ligament. Eur. J. Gynaecol. Oncol. 28 (5), 418-420.

Culhaci, N., Ozkara, E., Yuksel, H., Ozsunar, Y., Unal, E., 2006. Spontaneously ruptured uterine angioleiomyoma. Pathol. Oncol. Res. 12 (1), 50-51.

Duran, I., Tannock, I., 2006. Disseminated intravascular coagulation as the presenting sign of metastatic prostate cancer. J. Gen. Intern. Med. 21, C6-C8.

Hakverdi, S., Dolapcioglu, K., Gungoren, A., Yaldiz, M., Hakverdi, A.U., 2009. Multiple uterine angioleiomyomas mimicking an ovarian neoplasm: a case report. Eur. J. Gynaecol. Oncol. 30 (5), 592-594. 
Harris, M.G., Bannatyne, P., Russell, P., Atkinson, K., Rickard, A., Kronenberg, H., 1982. Chronic consumptive coagulopathy with a uterine leiomyoma. Aust. N. Z. J. Obstet. Gynaecol. 22 (1), 54-58.

Hsieh, C.H., Lui, C.C., Huang, S.C., Ou, Y.C., ChangChien, C.C., Lan, K.C., Huang, K.H., 2003. Multiple uterine angioleiomyomas in a woman presenting with severe menorrhagia. Gynecol. Oncol. 90 (2), 348-352.
Levi, M., Ten Cate, H., 1999. Disseminated intravascular coagulation. N. Engl. J. Med. 341, 586-592.

Ten Cate, H., Timmerman, J., Levi, M., 1999. The pathophysiology of disseminated intravascular coagulation. Thromb. Haemost. 82, 713-717.

Weiss, S.W., Goldblum, J.R., 2001. Benign tumors of smooth muscle, Enzinger and Weiss's Soft Tissue Tumors, 4th ed. Mosby, St. Louis. pp. 699-700. 